\title{
Real-World Treatment of Post-herpetic Neuralgia with Gabapentin or Pregabalin
}

\author{
Phaedra Johnson - Laura Becker • Rachel Halpern • \\ Michael Sweeney
}

Published online: 23 November 2012

(C) The Author(s) 2012. This article is published with open access at Springerlink.com

\begin{abstract}
Background and Objectives There are limited data examining the real-world use of gabapentin and pregabalin for the treatment of post-herpetic neuralgia (PHN). This study examines dosing patterns, therapy outcomes, healthcare utilization and costs of patients with PHN who initiate treatment with gabapentin or pregabalin.

Methods This was a retrospective administrative claims data analysis from July 2005 to February 2010. Patients with PHN initiating gabapentin or pregabalin (index therapy) from January 2006 to February 2009 were identified and were observed for 12 months after index therapy initiation. Outcomes were mean daily dosages of the index therapy, attainment of minimally effective dosages of gabapentin $(\geq 1,800 \mathrm{mg} /$ day $)$ or pregabalin $(\geq 150$ and $\geq 300 \mathrm{mg}$ /day) persistence, discontinuation, index therapy switching, addition of neuropathic pain medications to index therapy, and healthcare resource use and costs.

Results 1,645 patients were identified. The mean daily dosage was $826 \mathrm{mg}$ for gabapentin and $187 \mathrm{mg}$ for pregabalin. Only $52.6 \%$ of patients initiating gabapentin and $56.9 \%$ initiating pregabalin obtained a refill during the post-index period. Approximately $14 \%$ of patients treated with gabapentin reached the target dosage $(1,800 \mathrm{mg} /$ day $)$.
\end{abstract}

Electronic supplementary material The online version of this article (doi:10.1007/s40261-012-0030-4) contains supplementary material, which is available to authorized users.

P. Johnson $(\varangle) \cdot$ L. Becker $\cdot$ R. Halpern

Health Economics and Outcomes Research, OptumInsight,

12125 Technology Drive MN002-0258, Eden Prairie,

MN 55344, USA

e-mail: phaedra.johnson@optum.com

M. Sweeney

Depomed, Inc., Menlo Park, CA, USA
For pregabalin, $87 \%$ reached $\geq 150 \mathrm{mg} / \mathrm{day}$ and $27 \%$ reached $\geq 300 \mathrm{mg} / \mathrm{day}$. On average, patients took 10 weeks to reach $1,800 \mathrm{mg} /$ day gabapentin, and 5.0 and 9.2 weeks to reach $\geq 150 \mathrm{mg} /$ day and $\geq 300 \mathrm{mg} /$ day pregabalin, respectively. Approximately one-third of patients in both index therapy cohorts added a pain medication; more than half added opioids. The percentage of patients switching from either drug $(57 \%)$ or adding a therapy $(34 \%)$ were similar between index therapy cohorts; opioids were the most common therapy patients switched to or added.

Conclusion It appears that gabapentin and pregabalin are not used effectively to treat PHN. Suboptimal dosing and discontinuation may be associated with supplementary use of other analgesics, especially opioids.

\section{Introduction}

Approximately $2-3 \%$ of the US population suffers from neuropathic pain [1]. A common cause of neuropathic pain is post-herpetic neuralgia (PHN), a complication of herpes zoster. PHN may persist for weeks, or years, after the initial shingles rash has healed [2]. Although studies have demonstrated that the overall incidence of PHN following acute zoster is approximately $20 \%$, the incidences of PHN for individuals over the age of 50 and 75 years are as high as 40 and $75 \%$, respectively [3-6]. Because of the acute pain associated with PHN, quality of life is often negatively affected. In addition, PHN may interfere with daily activities, and may lead to insomnia, fatigue, depression and anxiety [7].

Antiepileptic medications and tricyclic antidepressants have been the mainstay of pharmacological treatment of neuropathic pain. Gabapentin and pregabalin are the only US Food and Drug Administration (FDA)-approved antiepileptics indicated for the treatment of neuropathic pain. 
Gabapentin and pregabalin are oral agents that bind to the $\alpha 2 \delta$ subunit of calcium channels in neurons and are believed to regulate neurotransmitter levels [8]. In two large multicentre studies, patients with PHN treated with gabapentin experienced significant reductions in pain compared with patients receiving placebo $[9,10]$. Patients on gabapentin also showed significantly less sleep interference and improvements in mood $[11,12]$. Pregabalin has been shown to be effective and tolerable in patients treated for neuropathic pain associated with PHN [13]. The beneficial effect of tricyclic antidepressants (e.g., amitriptyline, nortriptyline) in PHN treatment has also been demonstrated in several clinical trials [14-17].

This study used a large administrative claims database from a national US health plan to examine dosing patterns, therapy outcomes, and healthcare utilization and costs among patients with PHN treated with gabapentin and pregabalin. Because both gabapentin and pregabalin must be titrated to an effective dosage and continued for an adequate duration to alleviate the pain associated with PHN, we were interested to determine how many patients with PHN receive effective dosages of these therapies and how long they continue them in real-world practice. Furthermore, we examined which additional therapies were added to gabapentin or pregabalin or to what other therapies patients switched. Opioid analgesics, which are not first-line therapies for PHN, are also efficacious [18-20], but secondline use of them is controversial because of their risk for potential abuse, concerns regarding their long-term safety, and side effects such as constipation, nausea and drowsiness. Finally, we examined the costs for patients with PHN initiating treatment with gabapentin or pregabalin.

\section{Methods}

\subsection{Study Design and Data Source}

This was a retrospective claims database study using medical and pharmacy claims data and enrollment information from a proprietary claims database affiliated with OptumInsight. Individuals covered by this health plan, 26.9 million adults during the study period, were geographically diverse, with greatest representation in the South and Midwest US census regions. All study data were accessed using techniques compliant with the Health Insurance Portability and Accountability Act of 1996, and no identifiable protected health information was extracted for this study [21]. As such, this study was exempt from Institutional Review Board approval.

\subsection{Patient Identification}

The study population was commercially insured and Medicare Advantage health plan members with PHN initiating treatment with gabapentin or pregabalin. Patients had one or more pharmacy claim for either drug during the identification period of January 2006 to February 2009; the date of the first observed pharmacy claim was defined as the index date and the medication was defined as the index therapy. Patients were continuously enrolled in the health plans, with medical and pharmacy benefits, for at least 6 months before the index date (pre-index period) and 12 months after the index date (post-index period; included the index date). They had more than one medical claim with a primary International Classification of Diseases, Ninth Revision, Clinical Modification (ICD-9-CM) diagnosis for PHN $(053.1 \times)$ from the start of the pre-index period through 2 days after index date, and no claims for the index therapy during the pre-index period [22]. The entire period of observation was 1 July 2005 through 27 February 2010; each patient was observed for 18 months.

\subsection{Study Measures}

\subsubsection{Demographic and Clinical Characteristics}

Age, sex and US census region of health plan enrollment were obtained from enrollment data. A Charlson co-morbidity index score was calculated from ICD-9-CM diagnosis codes on medical claims in the pre-index period [23, 24]. Pharmacy claims were examined to identify pre-index use of non-index medications that could be prescribed for pain (see Appendix 1, Online Resource).

\subsubsection{Dosing Patterns}

Index therapy dosing patterns were measured during the post-index period. All dosing variables were based on calculations of mean daily dosage. Mean daily dosage for each index therapy fill was computed as: [(drug strength $\times$ quantity dispensed)/days supply]. Mean daily dosage for each day a patient possessed the index therapy was recorded; if a patient possessed the index therapy from more than one prescription fill on any given day, we assumed that gabapentin or pregabalin were being titrated and, consequently, the mean daily dosage values associated with each fill were summed for that day.

"Mean dosage while in possession," was computed as: [ $\sum$ (each day's mean daily dosage value)/number of days possessed]; days when patients did not possess index therapies (i.e., mean daily dosage $=0$ ) were excluded. "Mean daily dosage excluding gaps of $\geq 30$ days" was calculated using the equation above but excluding days when patients did not possess their index therapies if those days represented a minimum 30-day gap in therapy. Mean maximum dosage was the highest mean daily dosage value observed for at least 14 consecutive days; mean maximum dosage was not computed for patients with fewer than 14 
consecutive days of the same dosage. Time to mean maximum dosage was the number of days from the index date to the first day of the mean maximum dosage. Dose reduction occurred when mean daily dosage dropped from the mean maximum dosage by $\geq 300 \mathrm{mg}$ for gabapentin and by $\geq 150 \mathrm{mg}$ for pregabalin $[25,26]$.

Patients who received minimally effective dosages of index therapies were identified. A minimally effective dosage was defined as an individual fill of the index therapy with a mean daily dosage of the labeled minimally effective dosage for PHN $(\geq 1,800 \mathrm{mg}$ for gabapentin and $\geq 150 \mathrm{mg}$ for pregabalin) $[25,26]$. For pregabalin, an alternative minimally effective dosage threshold of $\geq 300 \mathrm{mg} /$ day was also examined; this dosage has similar efficacy to the effective dosage of gabapentin [25, 26]. Patients who did not have one or more index therapy pharmacy claim with a minimally effective dosage of either therapy were considered to have attained sub-therapeutic dosages.

\subsubsection{Therapy Outcomes}

Discontinuation, persistence, switch from index therapy and addition of pain medications (other than pregabalin and gabapentin) to the index therapy were measured during the post-index period. Discontinuation of index therapy was defined as a gap in therapy of at least 30 days. The discontinuation date was defined by the "run-out date" (i.e., fill date + days supply) of the last index therapy fill prior to the first observed gap. Discontinuation could occur between two consecutive therapy fills or between the last observed index therapy fill and the end of the post-index period. Persistence was the number of days from the index date to the discontinuation date. Index therapy switch was defined as at least one pharmacy claim for a non-index neuropathic pain medication (Appendix 1, Online Resource) and no subsequent index therapy fills. The class of medication to which the patients switched was identified. Neuropathic pain medication additions were defined as at least one claim for a condition-specific non-index therapy after the index date (not including the index therapy), prior to discontinuation of the index therapy, and no fills of the added therapy during pre-index period (Appendix 1, Online Resource).

\subsubsection{Cost and Utilization Outcomes}

All-cause healthcare resource utilization and costs were measured in the pre- and post-index periods. Inpatient stays, emergency room (ER) visits, outpatient facility visits, and physician office visits were counted per PHN patient per month. Costs per PHN patient per month were the sum of health plan and patient-paid amounts and were adjusted to 2009 US dollars using the Consumer Price Index [27]. Cost measures included inpatient costs, ER visit costs, outpatient facility visit costs, physician office visit costs, other services costs, total medical costs, outpatient pharmacy costs, and total healthcare (medical + pharmacy) costs.

\subsection{Analysis}

Variables were analysed descriptively. Results were stratified by index therapy cohort and, within cohort, by patients who received minimally effective and sub-therapeutic index therapy dosages. $T$ tests were used to identify significant differences between the means of continuous variables; chisquared statistics were used for binary variables.

\section{Results}

\subsection{Dosing Patterns and Therapy Outcomes}

A total of 1,645 patients (939 patients receiving gabapentin and 706 receiving pregabalin) met the study inclusion criteria (Fig. 1). Pre-index demographic and clinical characteristics are shown in Table 1. Detailed dosing patterns and therapy outcomes by index therapy cohort are shown in Table 2. The mean daily dosage excluding any gaps of 30 days was $826 \mathrm{mg}$ for gabapentin and $187 \mathrm{mg}$ for pregabalin. On average, it took patients 30.2 days to reach the mean maximum dosage of gabapentin $(969.5 \mathrm{mg})$ and 30.3 days to reach the mean maximum dosage of pregabalin $(221.8 \mathrm{mg})$. Patients receiving gabapentin or pregabalin remained on the therapy for an average of 72.9 and 79.5 days, respectively $(p=0.160)$. Patients treated with gabapentin $(10 \%)$ were more likely to have their dosages reduced than were patients receiving pregabalin (4\%, $p<0.001$ ).

The mean daily dosages for the first fills of gabapentin or pregabalin were $760 \mathrm{mg}$ and $175 \mathrm{mg}$, respectively (Appendix 2, Online Resource). Only slightly more than half of all patients had more than one fill of their index therapies (Fig. 2). Patients treated with gabapentin appeared to experience upward dosage titration through the first five fills of therapy, whereas patients treated with pregabalin appeared to be titrated upward for the first six to seven fills of therapy based on the mean dosage. Over half of patients switched from their index therapies during the post-index period (Fig. 3; Table 2). Of those who switched, approximately one-third switched to opioids (gabapentin, $35 \%$; pregabalin, $31 \% ; p=0.258$; Fig. 4a). Additionally, $37 \%$ of patients in the gabapentin cohort and $31 \%$ of patients in the pregabalin cohort added medication to their index therapies (Table 2); opioids were added by $57 \%$ of patients taking gabapentin and $58 \%$ of patients taking pregabalin (Fig. 4b). 


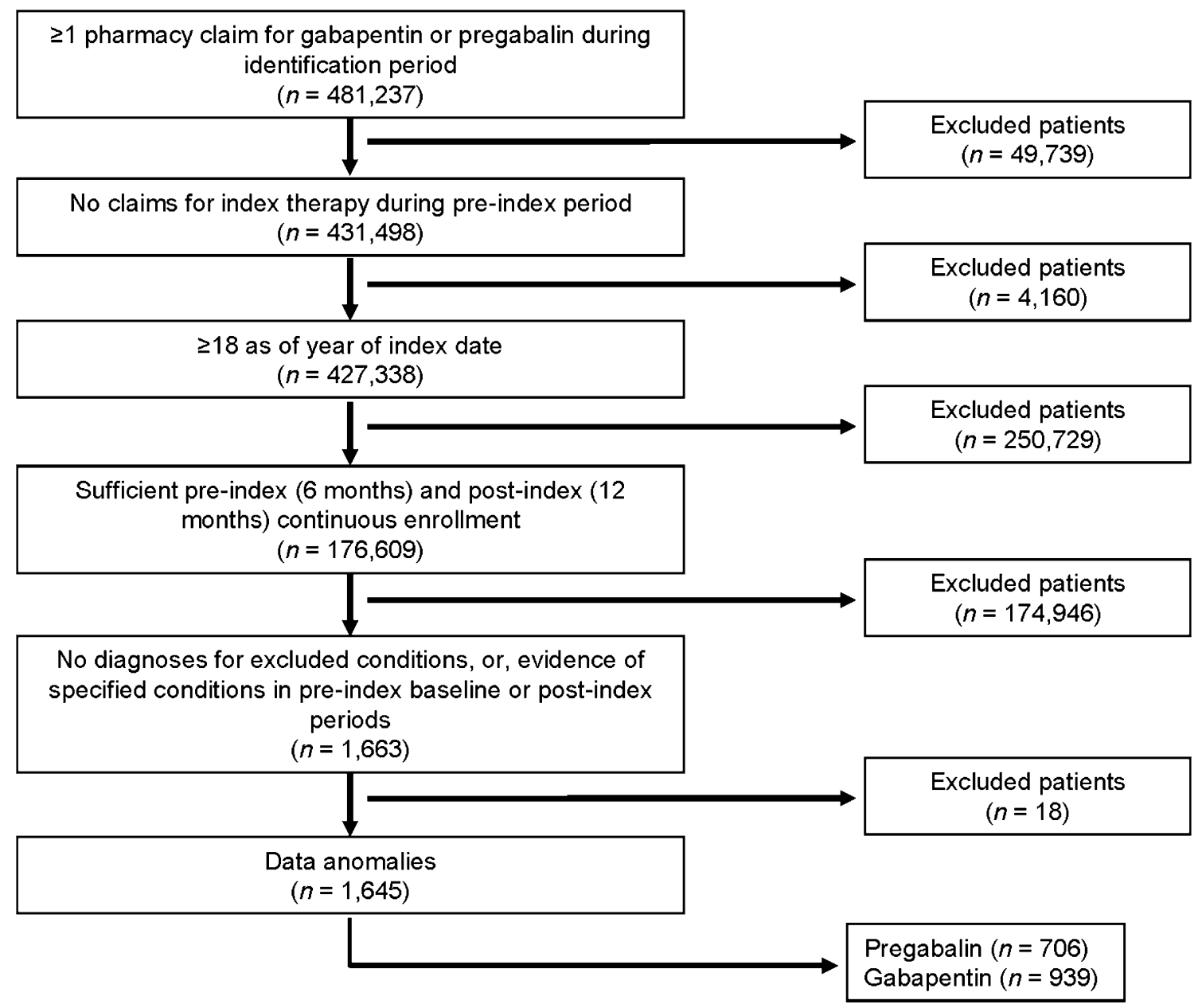

Fig. 1 Sample selection and attrition

3.2 Dosing Patterns and Therapy Outcomes of Patients Receiving Minimally Effective and Subtherapeutic Dosages of Therapy

Only $134(14 \%)$ patients taking gabapentin received at least one fill of the minimally effective dosage ( $\geq 1,800 \mathrm{mg} /$ day) and the mean time to reach this dosage was about 10 weeks (Table 3). In contrast, 611 (87\%) of patients taking pregabalin received at least one fill of the minimally effective dosage of $\geq 150 \mathrm{mg} /$ day and $194(27 \%)$ had at least one fill at $\geq 300 \mathrm{mg} / \mathrm{day}$. The mean times to reach daily dosages of $\geq 150 \mathrm{mg}$ or $\geq 300 \mathrm{mg}$ of pregabalin were about 5 weeks and 9.2 weeks, respectively. Patients receiving sub-therapeutic dosages of gabapentin or pregabalin were more likely than those who had received a minimally effective dosage to be switched to antidepressants (data not shown; $0.2 \%$ minimally effective, $3 \%$ subtherapeutic; $p=0.004$ ) or opioids (data not shown; $27 \%$ minimally effective, $38 \%$ sub-therapeutic; $p<0.001$ ).

Patients treated with sub-therapeutic dosages of gabapentin $(94 \%)$ were more likely to have gaps in therapy than were those receiving minimally effective dosages (87\%, $p=0.002$; Table 4). The mean total days on index therapy and mean total number of fills for index therapy were significantly higher for patients treated with minimally effective dosages of gabapentin compared to those treated with sub-therapeutic dosages (all $p<0.001$ ). The mean total days on index therapy $(p=0.001)$ and mean total number of fills for index therapy $(p<0.001)$ were also significantly higher for patients treated with minimally effective dosages of pregabalin ( $\geq 150 \mathrm{mg} /$ day) compared with those treated with lower dosages.

\subsection{Healthcare Resource Use and Cost}

There were no differences in healthcare utilization between patients who were going to receive gabapentin or pregabalin in the pre-index period with the exception of the mean count of all-cause inpatient admissions, which were higher in patients receiving gabapentin compared with patients receiving pregabalin ( $p=0.012$; Table 5$)$. In the post-index period, patients receiving gabapentin had significantly 
Table 1 Demographic and clinical characteristics by index therapy cohort ${ }^{\mathrm{a}}$
NS not significant

${ }^{a}$ Values are $\mathrm{n}(\%)$ except where otherwise stated

b All 2-way continuous comparisons between gabapentin and pregabalin index therapy cohorts were performed using $t$ tests; comparisons of binary variables between cohorts were evaluated with chisquared statistics

c Continuous variable

\begin{tabular}{|c|c|c|c|}
\hline Characteristic & $\begin{array}{l}\text { Gabapentin } \\
(n=939)\end{array}$ & $\begin{array}{l}\text { Pregabalin } \\
(n=706)\end{array}$ & $P$ value $^{\mathrm{b}}$ \\
\hline Age, years $(\text { mean } \pm S D)^{c}$ & $63.82 \pm 15.01$ & $61.99 \pm 14.61$ & 0.014 \\
\hline \multicolumn{4}{|l|}{ Age, years } \\
\hline $18-44$ & $105(11.18)$ & $83(11.76)$ & NS \\
\hline $45-64$ & $380(40.47)$ & $334(47.31)$ & 0.006 \\
\hline$\geq 65$ & $454(48.35)$ & $289(40.93)$ & 0.003 \\
\hline \multicolumn{4}{|l|}{ Sex } \\
\hline Male & $368(39.19)$ & $299(42.35)$ & NS \\
\hline Female & $571(60.81)$ & $407(57.65)$ & NS \\
\hline \multicolumn{4}{|l|}{ Insurance type } \\
\hline Commercial & $693(73.80)$ & $583(82.58)$ & $<0.001$ \\
\hline Medicare advantage & $246(26.20)$ & $123(17.42)$ & $<0.001$ \\
\hline \multicolumn{4}{|l|}{ Region } \\
\hline Northeast & $88(9.37)$ & $57(8.07)$ & NS \\
\hline Midwest & $338(36.00)$ & $182(25.78)$ & $<0.001$ \\
\hline South & $370(39.40)$ & $369(52.27)$ & $<0.001$ \\
\hline West & $143(15.23)$ & $98(13.88)$ & NS \\
\hline $\begin{array}{l}\text { Quan-Charlson co-morbidity score } \\
(\text { mean } \pm \mathrm{SD})^{\mathrm{c}}\end{array}$ & $1.05 \pm 1.58$ & $0.90 \pm 1.36$ & 0.040 \\
\hline \multicolumn{4}{|l|}{ Quan-Charlson co-morbidity score } \\
\hline 0 & $495(52.72)$ & $383(54.25)$ & NS \\
\hline 1 & 204 (21.73) & 165 (23.37) & NS \\
\hline 2 & $111(11.82)$ & 83 (11.76) & NS \\
\hline 3 & $54(5.75)$ & $40(5.67)$ & NS \\
\hline 4 & $35(3.73)$ & $17(2.41)$ & NS \\
\hline$\geq 5$ & $40(4.26)$ & $18(2.55)$ & NS \\
\hline Pre-index opioid use & $646(68.80)$ & 504 (71.39) & NS \\
\hline
\end{tabular}

and that additional titration to $1,800 \mathrm{mg} / \mathrm{day}$ is often necessary for full efficacy [28, 29]. However, dosages of up to $3,600 \mathrm{mg} /$ day may be required in some patients [28, 29]. The recommended duration for gabapentin titration for PHN is 3-8 weeks [30]. Our study found that the mean daily dosage and average maximum dosage for patients receiving gabapentin were 826 and $969 \mathrm{mg}$, respectively, which both were lower than the labeled dosage of $1,800 \mathrm{mg}$. Only $14 \%$ of the patients receiving gabapentin were titrated to the minimally effective dosage of $1,800 \mathrm{mg}$ or higher; the average maximum dosage for them was 2,224 $\mathrm{mg}$ and it took approximately 10 weeks to reach this level. Patients who received the minimally effective dosage of gabapentin remained on therapy for an average of 17 weeks.

The recommended dosage of pregabalin for PHN is $150-300 \mathrm{mg}$ daily $[30,31]$. If pain relief is inadequate following 2-4 weeks of pregabalin at $300 \mathrm{mg} /$ day, the dosage may be increased to $600 \mathrm{mg}$ daily [13]. In our study, the mean daily dosage for patients taking pregabalin was $187 \mathrm{mg}$, the mean maximum dosage was $222 \mathrm{mg}$, and it took 30 days on average to reach the maximal level. Approximately $87 \%$ of patients achieved 
Table 2 Dosing patterns and therapy outcomes by index therapy cohort

\begin{tabular}{|c|c|c|c|}
\hline Variable & Gabapentin $(n=939)^{\mathrm{a}}$ & Pregabalin $(n=706)^{\mathrm{a}}$ & $P$ value $^{\mathrm{b}}$ \\
\hline Daily dose excluding any gaps of 30 days, $\mathrm{mg}$ (mean \pm SD) & $826.26 \pm 559.27$ & $187.08 \pm 102.88$ & - \\
\hline Daily dose while in possession, $\mathrm{mg}(\text { mean } \pm \mathrm{SD})^{\mathrm{c}}$ & $875.12 \pm 602.41$ & $199.51 \pm 109.68$ & - \\
\hline Time to maximum dose days (mean $\pm \mathrm{SD})^{\mathrm{d}}$ & $30.24 \pm 70.70^{\mathrm{e}}$ & $30.26 \pm 70.63^{\mathrm{f}}$ & - \\
\hline Maximum dose, $\mathrm{mg}(\text { mean } \pm \mathrm{SD})^{\mathrm{d}}$ & $969.52 \pm 737.66^{\mathrm{e}}$ & $221.83 \pm 146.55^{\mathrm{f}}$ & - \\
\hline Time on index therapy, days (mean $\pm \mathrm{SD})^{\mathrm{g}}$ & $72.87 \pm 93.52$ & $79.51 \pm 96.53$ & NS \\
\hline Number of fills for index therapy (mean $\pm \mathrm{SD})^{\mathrm{h}}$ & $3.08 \pm 3.18$ & $3.30 \pm 3.37$ & NS \\
\hline Reduction in dose of index therapy during post-index period $[\mathrm{n}(\%)]^{\mathrm{d}}$ & $87(9.93)^{\mathrm{e}}$ & $29(4.39)^{\mathrm{f}}$ & $<0.001$ \\
\hline Gap in therapy $[\mathrm{n}(\%)]$ & $877(93.40)$ & $661(93.63)$ & NS \\
\hline Switch from index therapy $[\mathrm{n}(\%)]$ & $544(57.93)$ & $394(55.81)$ & NS \\
\hline Added to index therapy $[\mathrm{n}(\%)]$ & $348(37.06)$ & $218(30.88)$ & 0.009 \\
\hline
\end{tabular}

NS not significant; - signifies statistical analyses not performed

${ }^{a}$ Number of patients used for statistical calculation except where otherwise stated

b $T$ tests were used to identify significant differences between the means of continuous variables; chi-squared statistics were used for binary variables

${ }^{c}$ Dose while in possession was the daily dose only on those days that the patient had the index drug (e.g. excluded all gap days, included gaps fewer than 30 days)

${ }^{\mathrm{d}}$ For patients with $\geq 14$ days on one maximum dose

e 876 patients

${ }^{f} 661$ patients

g Number of days prior to evidence of gap or switch from index medication

h Throughout the entire follow-up period

Fig. 2 Number of index therapy fills

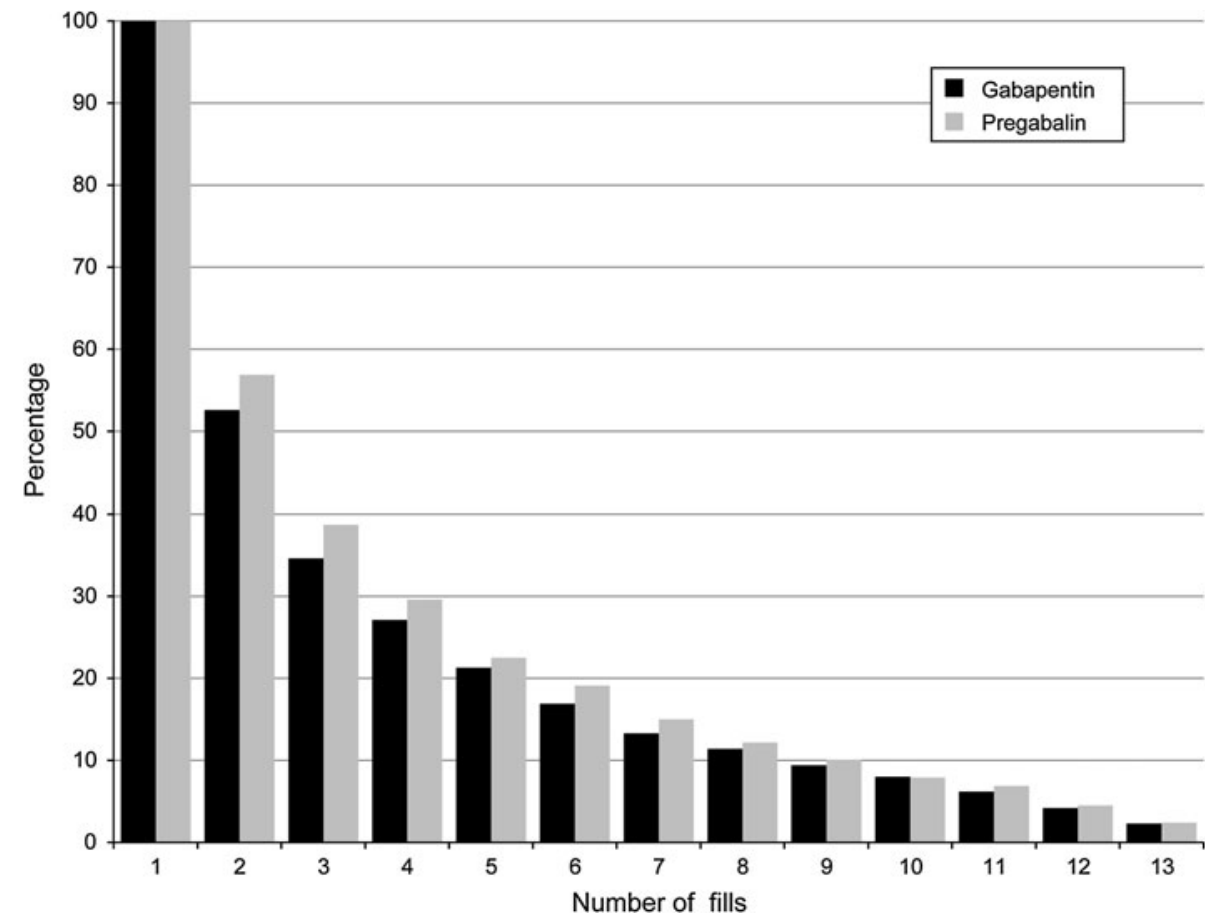

dosages of pregabalin $\geq 150 \mathrm{mg} / \mathrm{day}$, but only $27 \%$ of patients received dosages of pregabalin $\geq 300 \mathrm{mg} /$ day. The mean maximum dosage of patients receiving $150 \mathrm{mg} /$ day was $243 \mathrm{mg}$ and the average time to reach this maximum dosage was 33 days. Patients who received the minimally effective dosage of pregabalin ( $\geq 150 \mathrm{mg} /$ day) remained on therapy for an average of 12 weeks. 


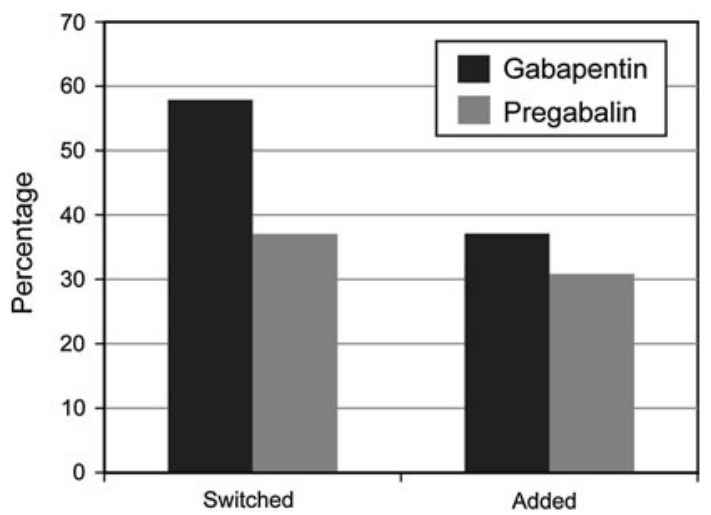

Fig. 3 Patients who added to or switched from index therapy
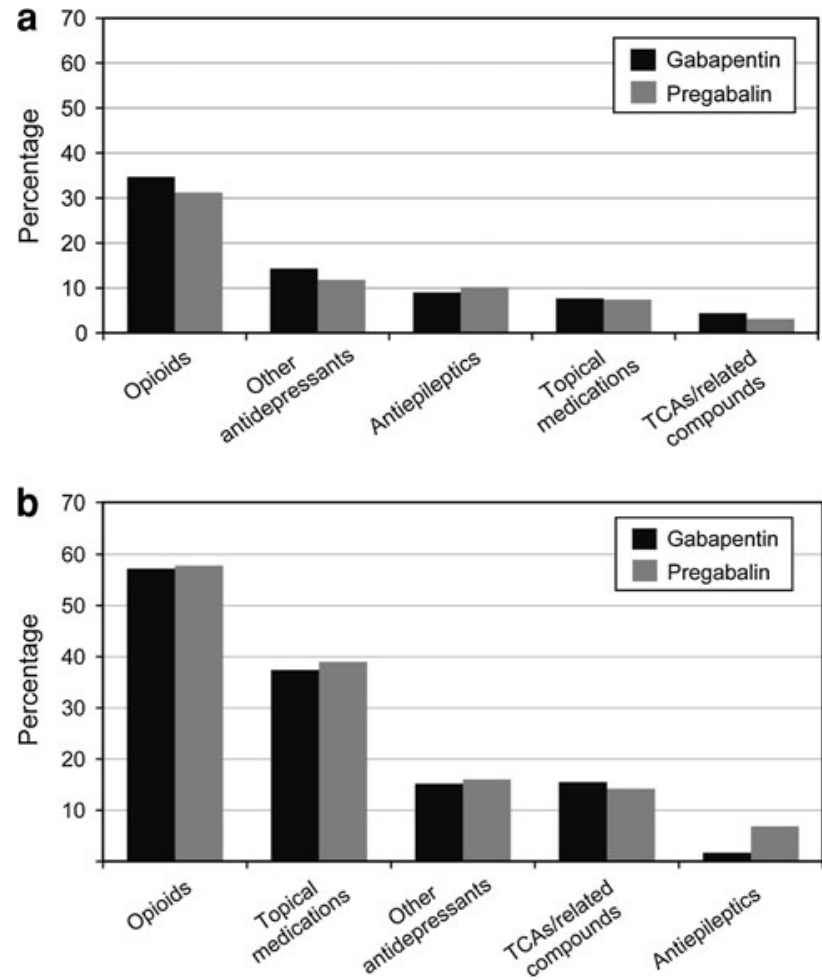

Fig. 4 Classes of medications $\mathbf{a}$ to which patients switched or $\mathbf{b}$ that were added to index therapy. TCA tricyclic antidepressants

Our data illustrate that many patients with PHN do not achieve the minimally effective dosage of gabapentin $(1,800 \mathrm{mg} /$ day $)$ or pregabalin at dosage levels $(\geq 300 \mathrm{mg} /$ day) with similar efficacy to the minimally effective dosage of gabapentin. This may have been due to several patient factors including co-morbidities, polypharmacy or issues with tolerability that would make it clinically unfeasible for a patient to reach a minimally effective dosage. Additionally, providers' clinical judgements about patients' analgesic responses at less than the labeled dosing levels, or without titration, may also be a factor when prescribing these therapies. Adverse events may be a contributing factor to why patients may not have achieved the minimally effective dosage following treatment initiation. Prior studies have shown that adverse events are a principal reason why people stop taking gabapentin or pregabalin [32]. However, some patients may have discontinued their medication rather than escalating to minimally effective dosage levels because they were not achieving sufficient pain management.

Half of the patients who took gabapentin or pregabalin in our study did not fill more than one prescription, and over half of the patients switched therapies. Of the patients who switched, one-third switched to opioids. A study by Gore et al. [33] focused specifically on the dosages prescribed in clinical practice and changes in the use of other neuropathic pain-related medications after the initiation of gabapentin or pregabalin and found similar results. In this study, patients with PHN increased opioid use after the initiation of gabapentin and decreased opioid use after the initiation of pregabalin. As in our study, more patients received a minimally effective dosage of pregabalin $(69 \%, \geq 150 \mathrm{mg} /$ day) than they did gabapentin ( $14 \%, \geq 1,800 \mathrm{mg} /$ day); however, our study found that a higher proportion of pregabalin patients added an opioid after treatment initiation than did those receiving gabapentin. Gore et al. [33] study also found that patients treated with pregabalin were more likely to attain therapeutic dosage levels earlier than were those patients who were prescribed gabapentin.

Our study was subject to certain limitations. The data used for this study come from a managed-care population and therefore the results may not be applicable to patients who are uninsured or underinsured. In addition, there are inherent limitations with the use of administrative claims data. First, some clinical and disease-specific parameters that might affect choice of treatment and study outcomes (e.g., adverse events, pain severity) are not available in claims data. Second, the presence of a diagnosis code on a medical claim is not a positive identification of a disease, as the diagnosis code may be incorrectly coded or codes may not precisely capture the diagnosis of interest or extent of disease. However, our analysis required a primary diagnosis that may have mitigated the likelihood of misclassification. Third, it is not possible to determine whether patients use medications as prescribed. Also, estimates of healthcare utilization and costs provided are all-cause, not PHN-specific. Lastly, in this study, opioids may have been used for other pain-related co-morbidities and it is possible that some patients did not reach optimal dosages because of side effects due to polypharmacy; these were not examined.

Current guidelines for pharmacological treatment of neuropathic pain are based on the results of randomized clinical trials and may not reflect "real-world" patterns of use in usual-care settings. Our results indicate that 
Table 3 Dosing patterns and therapy outcomes in patients receiving minimally effective doses of index therapy ${ }^{\mathrm{a}, \mathrm{b}}$

\begin{tabular}{|c|c|c|c|}
\hline Variable & $\begin{array}{l}\text { Gabapentin } \geq 1800 \mathrm{mg} / \text { day } \\
(n=134)^{\mathrm{c}}\end{array}$ & $\begin{array}{l}\text { Pregabalin } \geq 150 \mathrm{mg} / \text { day } \\
(n=611)^{\mathrm{c}}\end{array}$ & $\begin{array}{l}\text { Pregabalin } \geq 300 \mathrm{mg} / \text { day } \\
(n=194)^{\mathrm{c}}\end{array}$ \\
\hline Daily dose excluding any gaps of 30 days (mg) & $1710.87 \pm 836.42$ & $203.15 \pm 101.16$ & $310.66 \pm 116.15$ \\
\hline Daily dose while in possession $(\mathrm{mg})^{\mathrm{d}}$ & $1892.38 \pm 851.85$ & $217.06 \pm 107.41$ & $335.43 \pm 118.52$ \\
\hline Time to maximum dose (days) ${ }^{\mathrm{e}}$ & $68.94 \pm 89.26^{\mathrm{f}}$ & $33.18 \pm 73.01^{\mathrm{g}}$ & $64.54 \pm 95.26^{\mathrm{h}}$ \\
\hline Maximum dose $(\mathrm{mg})^{\mathrm{e}}$ & $2224.24 \pm 1,007.34^{\mathrm{f}}$ & $242.68 \pm 146.90^{\mathrm{g}}$ & $396.85 \pm 168.19^{\mathrm{h}}$ \\
\hline $\begin{array}{l}\text { Reduction in dose of index therapy during post- } \\
\text { index period }[\mathrm{n}(\%)]^{\mathrm{e}}\end{array}$ & $35(27.78)^{\mathrm{f}}$ & $29(5.08)^{\mathrm{g}}$ & $27(14.59)^{\mathrm{h}}$ \\
\hline \multicolumn{4}{|c|}{$\begin{array}{l}\text { a Minimally effective doses were defined as } \geq 1800 \mathrm{mg} / \text { day of gabapentin and } \geq 150 \mathrm{mg} / \text { day of pregabalin. Sub-therapeutic doses were defined } \\
\text { as less than the minimally effective daily dose }\end{array}$} \\
\hline \multicolumn{4}{|c|}{${ }^{\mathrm{b}}$ Values are mean $\pm \mathrm{SD}$ except where otherwise stated } \\
\hline \multicolumn{4}{|c|}{${ }^{c}$ Number of patients used for statistical calculation except where otherwise stated } \\
\hline \multicolumn{4}{|c|}{$\begin{array}{l}\text { d Dose while in possession was the daily dose only on those days that the patient had the index drug (e.g. excluded all gap days, included gaps } \\
\text { fewer than } 30 \text { days) }\end{array}$} \\
\hline \multicolumn{4}{|l|}{${ }^{\mathrm{e}}$ For patients with $\geq 14$ days on one maximum dose } \\
\hline \multicolumn{4}{|l|}{ f 126 patients } \\
\hline \multicolumn{4}{|l|}{ g 571 patient } \\
\hline h 185 patients & & & \\
\hline
\end{tabular}

Table 4 Dosing patterns and therapy outcomes in patients receiving minimally effective or sub-therapeutic doses of index therapy ${ }^{\mathrm{a}}$

\begin{tabular}{|c|c|c|c|c|c|c|}
\hline \multirow[t]{2}{*}{ Variable } & \multicolumn{3}{|l|}{ Gabapentin } & \multicolumn{3}{|l|}{ Pregabalin } \\
\hline & $\begin{array}{l}\text { Minimally effective } \\
(n=134)\end{array}$ & $\begin{array}{l}\text { Sub-therapeutic } \\
(n=805)\end{array}$ & $P$ value $^{\mathrm{b}}$ & $\begin{array}{l}\text { Minimally effective } \\
(n=611)\end{array}$ & $\begin{array}{l}\text { Sub-therapeutic } \\
(n=95)\end{array}$ & $P$ value $^{\mathrm{b}}$ \\
\hline Gap in therapy [n (\%)] & $117(87.31)$ & $760(94.41)$ & 0.002 & $568(92.96)$ & $93(97.89)$ & NS \\
\hline $\begin{array}{l}\text { Switch from index therapy [n } \\
(\%)]\end{array}$ & $68(50.75)$ & $476(59.13)$ & NS & $341(55.81)$ & $53(55.79)$ & NS \\
\hline $\begin{array}{l}\text { Time on index therapy, days } \\
(\text { mean } \pm \mathrm{SD})^{\mathrm{c}}\end{array}$ & $119.89 \pm 109.21$ & $65.04 \pm 88.32$ & $<0.001$ & $83.06 \pm 99.95$ & $56.71 \pm 66.74$ & 0.001 \\
\hline $\begin{array}{l}\text { Number or fills for index therapy } \\
(\text { mean } \pm S D)^{\mathrm{d}}\end{array}$ & $5.15 \pm 3.44$ & $2.74 \pm 3.00$ & $<0.001$ & $3.47 \pm 3.47$ & $2.24 \pm 2.47$ & $<0.001$ \\
\hline
\end{tabular}

$N S$ not significant

${ }^{a}$ Minimally effective doses were defined as $\geq 1800 \mathrm{mg} /$ day of gabapentin and $\geq 150 \mathrm{mg} /$ day of pregabalin. Sub-therapeutic doses were defined as less than the minimally effective daily dose

b Sub-therapeutic versus minimally effective dose within index therapy cohorts. All 2-way continuous comparisons between gabapentin and pregabalin index therapy cohorts were performed using $t$ tests; comparisons of binary variables were evaluated with chi-squared statistics

c Number of days prior to evidence of gap or switch from index medication

d Throughout the entire follow-up period

gabapentin and pregabalin are not being used effectively for the treatment of PHN. Sub-optimal dosing may lead to inadequate treatment response, which can in turn lead to early discontinuation of therapy, to switching to secondline therapies for PHN, or to addition of other analgesics. Taken together, these factors could possibly lead to unnecessarily high use of opioids which are currently "at the center of a major public health crisis of addiction, misuse, abuse, overdose and death" [34-36].

\section{Conclusion}

These findings show that many patients with PHN do not achieve the minimally effective dosages of gabapentin or pregabalin. The study also highlights possible issues with titration, the attainment of optimal dosages, and the tolerability of therapy in clinical practice. Further tolerability studies are warranted in studies of the pharmacological treatment of PHN. 
Table 5 Pre- and post-index healthcare utilization and costs per patient per month by index therapy ${ }^{\mathrm{a}}$

\begin{tabular}{|c|c|c|c|c|c|c|}
\hline \multirow[t]{2}{*}{ Variable } & \multicolumn{3}{|l|}{ Pre-index } & \multicolumn{3}{|l|}{ Post-index } \\
\hline & $\begin{array}{l}\text { Gabapentin } \\
(n=939)\end{array}$ & $\begin{array}{l}\text { Pregabalin } \\
(n=706)\end{array}$ & $P$ value $^{\mathrm{b}}$ & $\begin{array}{l}\text { Gabapentin } \\
(n=939)\end{array}$ & $\begin{array}{l}\text { Pregabalin } \\
(n=706)\end{array}$ & $P$ value $^{\mathrm{b}}$ \\
\hline \multicolumn{7}{|l|}{ All-cause healthcare utilization } \\
\hline Office visits & $1.38 \pm 1.35$ & $1.44 \pm 1.24$ & NS & $2.61 \pm 3.29$ & $2.30 \pm 2.64$ & 0.033 \\
\hline Outpatient visits & $0.50 \pm 0.75$ & $0.48 \pm 0.72$ & NS & $0.82 \pm 3.11$ & $0.64 \pm 2.74$ & NS \\
\hline Inpatient admissions & $0.04 \pm 0.09$ & $0.03 \pm 0.07$ & 0.012 & $0.04 \pm 0.23$ & $0.04 \pm 0.41$ & NS \\
\hline Emergency room visits & $0.11 \pm 0.26$ & $0.11 \pm 0.28$ & NS & $0.24 \pm 1.11$ & $0.15 \pm 0.82$ & NS \\
\hline $\begin{array}{l}\text { All-cause total healthcare cost } \\
(\text { US } \$)^{\mathrm{c}}\end{array}$ & $1136 \pm 2598$ & $1007 \pm 1879$ & NS & $1749 \pm 6117$ & $1570 \pm 4935$ & NS \\
\hline All-cause pharmacy cost $(\mathrm{US} \$)^{\mathrm{c}}$ & $247 \pm 418$ & $251 \pm 345$ & NS & $423 \pm 755$ & $585 \pm 727$ & $<0.001$ \\
\hline All-cause medical cost $(\mathrm{US} \$)^{\mathrm{c}}$ & $889 \pm 2501$ & $756 \pm 1814$ & NS & $1326 \pm 5831$ & $985 \pm 4753$ & NS \\
\hline Inpatient stay & $337 \pm 1377$ & $277 \pm 1441$ & NS & $390 \pm 3136$ & $315 \pm 4101$ & NS \\
\hline Emergency room & $29 \pm 91$ & $27 \pm 82$ & NS & $61 \pm 350$ & $35 \pm 280$ & NS \\
\hline Outpatient visit & $266 \pm 1376$ & $226 \pm 566$ & NS & $454 \pm 4457$ & $327 \pm 1952$ & NS \\
\hline Office visit & $220 \pm 745$ & $193 \pm 412$ & NS & $336 \pm 1065$ & $258 \pm 497$ & 0.048 \\
\hline Other medical & $37 \pm 137$ & $34 \pm 116$ & NS & $86 \pm 704$ & $50 \pm 199$ & NS \\
\hline
\end{tabular}

Acknowledgments This study and the manuscript were funded by Depomed, Inc.

Open Access This article is distributed under the terms of the Creative Commons Attribution Noncommercial License which permits any noncommercial use, distribution, and reproduction in any medium, provided the original author(s) and the source are credited.

\section{References}

1. Bouhassira D, Lanteri-Minet M, Attal N, Laurent B, Touboul C. Prevalence of chronic pain with neuropathic characteristics in the general population. Pain. 2008;136(3):380-7.

2. Oxman MN. Herpes zoster pathogenesis and cell-mediated immunity and immunosenescence. J Am Osteopath Assoc. 2009;109(6 Suppl 2):S13-7.

3. Donahue JG, Choo PW, Manson JE, Platt R. The incidence of herpes zoster. Arch Intern Med. 1995;155(15):1605-9.

4. Scott FT, Leedham-Green ME, Barrett-Muir WY, Hawrami K, Gallagher WJ, Johnson R, et al. A study of shingles and the development of postherpetic neuralgia in East London. J Med Virol. 2003;70(Suppl 1):S24-30.

5. Lancaster T, Silagy C, Gray S. Primary care management of acute herpes zoster: systematic review of evidence from randomized controlled trials. Br J Gen Pract. 1995;45(390):39-45.

6. Portenoy RK, Duma C, Foley KM. Acute herpetic and postherpetic neuralgia: clinical review and current management. Ann Neurol. 1986;20(6):651-64.

7. Schmader KE. Epidemiology and impact on quality of life of postherpetic neuralgia and painful diabetic neuropathy. Clin $\mathrm{J}$ Pain. 2002;18(6):350-4.
8. Gale JD, Houghton LA. Alpha 2 Delta (alpha(2)delta) Ligands, Gabapentin and Pregabalin: What is the Evidence for Potential Use of These Ligands in Irritable Bowel Syndrome. Front Pharmacol. 2011;2:28.

9. Rowbotham M, Harden N, Stacey B, Bernstein P, Magnus-Miller L. Gabapentin for the treatment of postherpetic neuralgia: a randomized controlled trial. JAMA. 1998;280(21):1837-42.

10. Sang CN, Sathyanarayana R, Sweeney M. Gastroretentive gabapentin (G-GR) formulation reduces intensity of pain associated with postherpetic neuralgia (PHN). Clin J Pain. 2012 [Epub ahead of print].

11. Backonja M, Beydoun A, Edwards KR, Schwartz SL, Fonseca V, Hes $M$, et al. Gabapentin for the symptomatic treatment of painful neuropathy in patients with diabetes mellitus: a randomized controlled trial. JAMA. 1998;280(21):1831-6.

12. Rice AS, Maton S. Gabapentin in postherpetic neuralgia: a randomised, double blind, placebo controlled study. Pain. 2001;94(2):215-24.

13. Freynhagen R, Strojek K, Griesing T, Whalen E, Balkenohl M. Efficacy of pregabalin in neuropathic pain evaluated in a 12-week, randomised, double-blind, multicentre, placebo-controlled trial of flexible- and fixed-dose regimens. Pain. 2005;115(3):254-63.

14. Hempenstall K, Nurmikko TJ, Johnson RW, A'Hern RP, Rice AS. Analgesic therapy in postherpetic neuralgia: a quantitative systematic review. PLoS Med. 2005;2(7):e164.

15. Saarto T, Wiffen PJ. Antidepressants for neuropathic pain. Cochrane Database Syst Rev 2007;(4):CD005454.

16. Watson CP, Vernich L, Chipman M, Reed K. Nortriptyline versus amitriptyline in postherpetic neuralgia: a randomized trial. Neurology. 1998;51(4):1166-71.

17. Max MB, Lynch SA, Muir J, Shoaf SE, Smoller B, Dubner R. Effects of desipramine, amitriptyline, and fluoxetine on pain in diabetic neuropathy. N Engl J Med. 1992;326(19):1250-6. 
18. Watson CP, Babul N. Efficacy of oxycodone in neuropathic pain: a randomized trial in postherpetic neuralgia. Neurology. 1998; 50(6): 1837-41.

19. Raja SN, Haythornthwaite JA, Pappagallo M, Clark MR, Travison TG, Sabeen S, et al. Opioids versus antidepressants in postherpetic neuralgia: a randomized, placebo-controlled trial. Neurology. 2002;59(7):1015-21.

20. Boureau F, Legallicier P, Kabir-Ahmadi M. Tramadol in postherpetic neuralgia: a randomized, double-blind, placebo-controlled trial. Pain. 2003;104(1-2):323-31.

21. Public law 104-191 1C. Health insurance portability and accountability act of 1996. US Department of Health \& Human Services, editor. 2011.

22. The International Classification of Diseases, Ninth Revision, Clinical Modification. Health and Human Services Dept. 6th ed. Centers for Disease Control and Prevention; and Centers for Medicare and Medicaid Services. 2012.

23. Charlson M, Szatrowski TP, Peterson J, Gold J. Validation of a combined comorbidity index. J Clin Epidemiol. 1994;47(11): 1245-51.

24. Quan H, Sundararajan V, Halfon P, Fong A, Burnand B, Luthi JC, et al. Coding algorithms for defining comorbidities in ICD-9CM and ICD-10 administrative data. Med Care. 2005;43(11): $1130-9$.

25. Gabapentin label [online]. 2012. http://labeling.pfizer.com/ ShowLabeling.aspx ?id=630. Accessed 30 Aug 2011.

26. Pregabalin label [online]. 2012. http://www.pfizerpro.com/ resources/minisites/lyrica/docs/LYRICA_Dosing_Tool.pdf. Accessed 30 Aug 2011.

27. US Department of Labor BoLS. Consumer Price Index. Chained Consumer Price Index for all urban consumers (C-CPI-U) medical care. Series ID: CUUR0000SAM. 2009. http://www.bls.gov/data. Accessed 9 Aug 2011.

28. Backonja M, Glanzman RL. Gabapentin dosing for neuropathic pain: evidence from randomized, placebo-controlled clinical trials. Clin Ther. 2003;25(1):81-104.

29. Wiffen PJ, Collins S, McQuay HJ, Carroll D, Jadad A, Moore RA. WITHDRAWN. Anticonvulsant drugs for acute and chronic pain. Cochrane Database Syst Rev 2010;(1):CD001133.

30. Dworkin RH, O’Connor AB, Audette J, Baron R, Gourlay GK, Haanpaa ML, et al. Recommendations for the pharmacological management of neuropathic pain: an overview and literature update. Mayo Clin Proc. 2010;85(3 Suppl):S3-14.

31. Argoff CE. Review of current guidelines on the care of postherpetic neuralgia. Postgrad Med. 2011;123(5):134-42.

32. Selph S. CSFRTSLAMM. Drug Class Review: Neuropathic Pain: Final Update 1 Report. In: Oregon Health \& Science University, editor. Drug Class Reviews. Portland (OR). 2011.

33. Gore M, Sadosky A, Tai KS, Stacey B. A retrospective evaluation of the use of gabapentin and pregabalin in patients with postherpetic neuralgia in usual-care settings. Clin Ther. 2007;29(8): 1655-70.

34. Arkinstall W, Sandler A, Goughnour B, Babul N, Harsanyi Z, Darke AC. Efficacy of controlled-release codeine in chronic nonmalignant pain: a randomized, placebo-controlled clinical trial. Pain. 1995;62(2):169-78.

35. Moulin DE, Iezzi A, Amireh R, Sharpe WK, Boyd D, Merskey H. Randomised trial of oral morphine for chronic non-cancer pain. Lancet. 1996;347(8995):143-7.

36. Food and Drug Administration (FDA). FDA risk evaluation and mitigation strategies (REMS) for extended-release and long-acting opioid analgesics. 2010. 